\title{
PAISAGENS SOCIAIS E A EXPERIÊNCIA EVANGÉLICA NA MÍDIA: COSMOVISÕES DE UM DISCURSO COMPETENTE
}

- RITA GONÇALO*

Resumo: Este trabalho tem por objetivo explorar como os evangélicos produzem uma paisagem social utilizando-se, para isso, dos canais de mídia. Televisão, redes sociais e plataformas de streaming, por exemplo, têm sido usadas para dialogar sobre questões morais e relacionais, as quais figuram, particularmente, como uma preocupação cotidiana e constitutiva da experiência urbana evangélica nos dias atuais. $O$ conceito de paisagem aqui é analisado a partir de uma perspectiva antropológica, de modo a demonstrar que os diferentes panoramas construídos pelos evangélicos são um fenômeno histórico indissociável da emergência da hipermodernidade, pautada pelos ideais de transformação do mundo e formulação de práticas para a sobrevivência da religião nas próximas gerações. Com base nas reflexões desenvolvidas por teóricos como Robert Pechman (2002) e JeanMarc Besse (2016), descrevo as estratégias que grupos evangélicos ligados aos núcleos de poder governamental e de influência midiática elaboram para elaborar certa espécie de projeto de "poder urbano", no sentido de terem um lugar de fala e de práticas que negociam e fazem valer sua presença na cidade.

Palavras-chave: Evangélicos; Urbanidade; Poder urbano; Paisagem.

\section{Introdução}

Tradicionalmente, os termos Urbe e seu derivado, Urbanidade, estão associados à cidade de forma análoga. Fazer sua distinção, entretanto, nos ajuda a construir outras definições para a cidade contemporânea e, por extensão, compreender o lugar de grupos influentes nela. $\mathrm{O}$ termo Urbe nos remete à materialidade da cidade: seus equipamentos, serviços e construções físicas nos territórios onde os cidadãos vivem, prioritariamente oferecidos pelo Estado (e, também, pelo mercado). Do sentido da Urbe 
vem a palavra Urbanização, que diz respeito à remodelação dessa materialidade da cidade; seus processos de transformação física, de renovação do tecido urbano, de intervenção.

Todavia, a cidade não é apenas materialidade, sua Urbe. Ela também é suas relações sociais, as formas de contato e ação comum no espaço público, as relações de cooperação e solidariedade, relações comunitárias e políticas. Tudo isso se revela como Urbanidade, que, por sua vez, se refere a comportamentos na cidade, formas de perceber o convívio com o outro. A Urbanidade remete para as ideias de cidadania e civilidade, convivência e sociabilidade (PECHMAN, 2002). Urbanidade é uma decorrência do que seria o urbano, e urbano é o ser e o estar na cidade, (Cf. HEIDEGGER, 1995). A urbanidade é a maneira de ver o outro com todos os seus desdobramentos: a confiança e a solidariedade, mas também o espírito público de regulação e de ordem. Remete a um "sistema de idéias com articulações e conceitos 'inventados' para nomear uma nova ordem que se gesta” (PECHMAN, 2002, p. 126).

Com esse viés epistemológico, em 2017 teve início minha pesquisa de doutorado sobre a urbanidade gospel, onde procuro entender como os evangélicos produzem uma ordem social e urbana a partir de certos mecanismos e construção de paisagens. A paisagem proposta por mim é analisada com base em uma perspectiva antropológica. Bebendo de fontes como o filósofo Jean-Marc Besse (2016) e o historiador Robert Pechman (2002) entendo que as diferentes paisagens construídas pelos evangélicos são um fenômeno histórico indissociável da emergência da chamada hipermodernidade (LIPOVETSKY 2004), como uma tensão entre o viver o presente e as reações ao futuro, pautada pelos ideais de transformação e formulação de práticas para a sobrevivência da religião nas próximas gerações. Frente a isso, os evangélicos especialmente os grupos ligados aos núcleos de poder governamental e de influência midiática - estão cada vez mais mobilizados por forças de intervenção e reordenamento na metrópole. Eles observam o presente e pensam estratégias para mitigar, no futuro, os "males da cidade", onde as questões morais e relacionais figuram, particularmente, como uma preocupação cotidiana e constitutiva.

Por meio de dispositivos do legislativo, operações de mídia televisiva e web, construção de mega catedrais e implementação de ações de bem-estar social, percebe-se que estes meios se constituem como arenas onde os evangélicos empreendem um notável esforço por articular a urbanidade mais do que o próprio processo de urbanização. Mediante à crise da incapacidade institucional e o divórcio entre o Estado 
e a política como ação efetiva para o bem-estar entre os homens, a cidade e o Brasil, para os evangélicos, estariam enfermos. Contaminados por uma doença moral e uma doença ética. Neste sentido, o presente artigo busca considerar alguns espectros onde a paisagem produzida pelos evangélicos na cena política contemporânea é considerada como um recurso para as estratégias de ordenamento do espaço da cidade. A paisagem evangélica ocupa, na atualidade, um lugar crucial nas preocupações sociais e políticas, e no cuidado em relação ao questionamento sobre a identidade da família e dos cidadãos.

A hipótese que formulamos é a de que está voga uma nova cultura da paisagem (BESSE, 2016), que corresponde a novas formas de experiência do espaço em sociedade. Posto isso, a relação com as paisagens evangélicas ficou mais complexa, uma vez que elas são políticas, midiáticas, arquitetônicas, e, também, relacionais.

Tendo em vista a amplitude do fenômeno no cenário brasileiro, optei pelo estudo analítico de alguns cases midiáticos-políticos originários de igrejas evangélicas históricas do sul do país e de personalidades de igrejas neopentecostais no Rio de Janeiro. Embora a amostragem não possa ser tomada como representativa do todo, considero a validade das homologias estruturais do campo evangélico nos termos de Bourdieu (1997), ou seja, os atributos e comportamentos desta amostra podem ser similarmente verificados em outras correntes denominacionais.

As apresentações que se seguem resultam de uma metodologia baseada em ferramentas mistas do fazer quanti-qualitativo: i) etnografia urbana (observação participante, relatos de campo e entrevistas semiestruturadas); ii) levantamento em surveys de opinião pública, e; iii) exploração de conteúdo em ambiente digital (netnografia), com acompanhamento das dinâmicas de lideranças evangélicas em canais de TV e redes sociais como YouTube e Instagram. Os cases contribuíram para mostrar que a paisagem evangélica se tornou, de modo geral, moldada por um "tecido ético" a fim de reformular uma miríade de conceitos sobre as formas de experiência social e moral a serem vividas no urbano, resultando assim numa polissemia e mobilidade essenciais para compreensão do conceito de paisagem na hipermodernidade. 


\section{Imaginários do urbano: o "mal” na cidade}

Uma das tendências mais marcantes das teorias que analisaram a cidade enquanto categoria social foi a de encará-la como uma variável explicativa. Na tradição do pensamento sobre a cidade pode-se identificar, basicamente, três tipos-ideais: 1) a noção grega de polis, uma comunidade agrourbana baseada em uma entidade política de grupos funcionalmente integrados; 2) a noção romana de municipalidade (civitas) como instrumento para "civilizar" os povos rurais; 3) a noção agostiniana de uma cidade de Deus $s^{l}$ cujos ideais cristãos e esforços pietistas se opunham aos males da vida terrena. A “Cidade de Deus" idealizada em Santo Agostinho aproxima-se bastante das reflexões que se seguirão neste trabalho, sendo essa alegoria um dos primeiros referenciais metodológicos a tentar explicar que, em quaisquer prospectos de cidade, só existe a unidade social e política nas sociedades que aderem a "verdadeira" religião, isto é, o ideário cristão.

O valor de uma cidade, segundo Agostinho, se mede "pelo valor dos objetos que amam, isto é, pela qualidade do amor que nela impera” (CIDADE DE DEUS, LIVRO XIX, p. 24). Os membros da "cidade diabólica amam a glória humana", e os membros da cidade de Deus, ao contrário, "amam as coisas celestiais" (op. cit., LIVRO XIV, p. 28). Em uma perspectiva binária, esses discursos significam que entre os cidadãos da cidade terrena predomina o amor às coisas temporais, e entre os cidadãos da cidade celestial existe o amor a Deus na caridade (GILSON, 1965). Neste sentido, quando as cidades não compartilham de um ethos cristão elas perdem a sua base moral, donde vem, portanto, a decadência, que se expande para outros campos da vida social, política e econômica.

Quando Santo Agostinho fala das duas cidades ou sociedades, ele quer "expressar a existência de duas comunidades motivadas por atitudes mentais e morais divergentes" (COELHO, 2012, p. 124). A sociedade humana é interpretada por Agostinho através desse simbolismo moral, de tensões entre dois cenários históricos o mundano e o extraterreno, a cidade dos homens e a cidade de Deus. Agostinho apresenta a cidade de Deus de forma positiva - cidade celeste, sociedade dos santos, gloriosa cidade, Jerusalém celeste, Jerusalém suprema -, em oposição à sua alteridade, a cidade terrena, representada como a Babel na qual existia desordem, confusão e divisão de línguas. Para o autor, somente no grupo da cidade celestial existiria unidade, caridade, honestidade, coerência e justiça, indicando que o bispo concebia que somente 
existe verdadeira justiça onde se houver assentado o culto cristão. Consequentemente, nas sociedades em que não foi instaurada a verdadeira religião - o Cristianismo - estas seriam marcadas pela anomia religiosa, social e política.

Em linhas gerais, sua tese racionalista deriva que o bem-estar e o sucesso de um povo são contingentes, principalmente, a fatores tais como ética, moralidade, o progresso material e a eficiência produtiva e econômica. Ele entendia a cidade como detentora da função civilizatória, ao introduzir leis e um modo de vida em comunidade com defesa e ajuda mútuas, estabelecendo relações voluntárias de engajamento e conectando-as a estruturas maiores de ordem jurídica e administrativa. Em suas palavras, a cidade seria eminentemente civilizatória, assentada em uma missão benigna: a de fornecer os arranjos contratuais que contemplem o desenvolvimento de uma identidade de comunidade; a pólis como personificação da justiça social. Sendo assim, ao visionar a cidade de Deus, Santo Agostinho admitia que o Novo Mundo, a cidade ideal, era onde os princípios morais são reforçados. Para Agostinho, a cidade cresce a partir das lealdades políticas.

A questão do mal na cidade e do combate às degradações morais é, portanto, muito antiga, e não essencialmente evangélica, posto que diferentes pensadores atribuíram à cidade o poder de criar uma cultura urbana marcada fundamentalmente pela desorganização social e cultural (OLIVEN, 2011). Aristóteles na Política (2006, p. 235) falava que "a cidade se equilibra entre o vício e a virtude". Na modernidade europeia e na experiência urbana brasileira do início do século XX, esses princípios também estiveram presentes. No caso europeu as cidades da Revolução Industrial despontam com uma virulência muito grande, porque todas as interdições estão sendo destruídas, principalmente no campo moral. Na França da primeira metade do século XIX, têm-se uma preocupação muito grande com a contaminação, seja moral ou física. Definiam o conhecimento, circunscreviam o problema e apontavam soluções para questões como prostituição, sífilis, doenças sexuais, aborto, lascívia. A ideia presente era intervir para transformar, remodelar, recuperar. Um debate forte que atravessava diferentes países.

Aqui no Brasil, nos anos 1860 Joaquim Manuel de Macedo, romancista urbano, escreve na imprensa uma série de artigos sobre os males da cidade. Toda a obra dele é no sentido de ensinar uma moral urbana. No livro A luneta mágica, o protagonista Simplício, que é míope, descobre um bruxo que fabrica uma luneta mágica, onde se pode escolher o espectro de visão desejado: enxergar ou só o bem ou só o mal. O 
protagonista experimenta a luneta com os dois imperativos morais, e com isso vê o mundo somente pelo ângulo do bem - e aí se torna um crente esperançoso - ou apenas pelo ângulo do mal - e então se torna um incrédulo de tudo e qualquer coisa que existe na Terra. Esse romance mostra o quanto as pessoas fundam um juízo de valor ao olhar a sociedade para discernir entre o bem e o mal.

O teatrólogo Artur de Azevedo escreve, em 1900, o livro chamado A capital federal, que mostra como um casal de mineiros do interior se perde - física e moralmente - na cidade. A cidade, aqui, é esse lugar de perdição. Mas também é o lugar da razão, da invenção, do conforto, da urbanidade, da superação da mesmice, o lugar da novidade, da modernidade. Mais adiante, nas décadas de 1910-20 surge no Brasil o movimento ruralista, uma ideologia da volta para o campo, porque a cidade está infestada de comunistas, de movimentos operários, de uma língua que não é o português; hábitos que não são os nossos, estrangeirismos (SEVCENKO, 1992). Nos jornais, na literatura, vemos a mesma questão colocada diante dos novos perigos da cidade em vários aspectos da política, da vida pública, do comportamento e dos costumes.

Vemos também, a partir da década de 20, uma forte intervenção da Igreja Católica nas questões da cidade. Os pensadores leigos e religiosos da Igreja começam a dar-se conta de que a partir desse período - com a criação do Partido Comunista, a Semana da Arte de 1922, o tenentismo - os grandes movimentos político-ideológicos de discussão da sociedade trazem à tona a sensação de que os católicos estão perdendo a disputa. A esquerda sobe aos morros, conscientizando as pessoas, propondo políticas de habitação. Quando os problemas urbanos no Brasil vêm à tona, no primeiro quartel do século $\mathrm{XX}$, a Igreja constata que precisa intervir diretamente nessas questões. A intelectualidade católica passa a produzir toda uma reflexão sobre o país e sobre a necessidade de "cristianizar" o Brasil. O cerne da questão brasileira da época é a modernização das cidades e suas consequências - especialmente a inserção dos novos costumes no corpo social.

Encontra-se aí toda uma tradição de que na cidade a família vai se perder, a religião vai ser deixada de lado, a promiscuidade estará às soltas, a mulher será atraída pelo erotismo, entre outras preocupações. A sociedade brasileira da época, extremamente retrógrada e conservadora, vai se bater enormemente por esses ideais de pureza e não contaminação frente a ideias exógenas e não religiosas. Isso aparece 
nitidamente no teatro, no romance literário, na imprensa, na fala da igreja, e, posteriormente, nas discursividades do poder público governamental.

\section{O despontar dos evangélicos}

Essas tensões entre a cidade como o lugar da virtude e do vício - ou de equilíbrio entre o vício e a virtude - vão ecoar adiante com os evangélicos. A chegada dos cristãos evangélicos ao campo político foi precedida tanto pela criação de novas representações ideológicas, como por um descontentamento com as maneiras tradicionais de se fazer política no Brasil (SILVA, 2010, p. 103). Os evangélicos conseguiram penetrar um campo de interlocução com a sociedade abrangente onde vinham desde fins do século XIX - e, especialmente, após a segunda metade dos anos de 1950 - laboriosamente construindo credibilidade e legitimidade sociais, resultando em seguida na fala "autorizada" de lideranças pentecostais via organizações representativas de setores evangélicos nos anos 1980. A forte investida dos pentecostais sobre a política eleitoral pós-1988 e a posse de poderosos recursos de mídia contribuíram para eclipsar outras vozes não evangélicas.

Burity (2010) nos informa que, nas organizações cristãs evangélicas, a capilaridade e a distribuição pelo território permitiam "a formação de uma rede que começaria nos ministérios, secretarias de estado ou municipais e suas áreas de assistência social, de educação e cultura, para chegar até a ponta, aos cidadãos" (BURITY, 2010, p. 119). O cálculo estratégico aqui seria, portanto, conferir credibilidade a essas instituições religiosas, para que elas se tornassem uma rede que ligaria o Estado ao cidadão. Daí provém um acentuado protagonismo político que se justificou, explicitamente, pelo novo peso que os evangélicos vêm possuindo desde meados dos anos 1980. Peso social, decorrente de seu crescente número, e peso eleitoral, dada a sua capacidade de construir uma efetiva representação parlamentar em todos os níveis.

Assim, os grupos evangélicos tanto buscam inserir-se nesses espaços como são procurados como possuidores de saberes e de reconhecimento social politicamente instrumentais, ocupantes de lugares social e politicamente relevantes ou disputados. Eles estão construindo paisagens, um contexto de projeto, "uma realidade mental" (BESSE, 2016, p. 12) definida como um modo de pensar e de perceber o ethos cristão no urbano. Para citar alguns exemplos, há representações evangélicas no Conselho 
Nacional de Segurança Alimentar e Nutricional, no Conselho Nacional da Juventude; no Conselho de Transparência Pública e Combate à Corrupção, em conselhos estaduais e municipais em todos os estados da federação, além da participação em frentes de instância legislativa, como a Frente Parlamentar Evangélica do Congresso Nacional e as bancadas cristãs nas Assembleias Legislativas estaduais e Câmara de Vereadores (BURITY, 2010).

Outras ferramentas catalisadoras da expansão do cristianismo evangélico foram os canais de mídia (rádio e TV), pois, com a repressão que havia nas cidades durante e pós-ditadura militar, era bastante difícil realizar cultos e propalar mensagens evangelizadoras em lugares públicos. A estratégia deles foi, então, usar a mídia como canal de evangelização e de esperança para um futuro melhor, por isso houve a emergência de tantas igrejas e conversões de indivíduos durante os anos 60-80, em todas as camadas da população (destaque para o crescimento evangélico entre a classe média vide bispo Robert McAlister $^{2}$ ). Nessa passagem verifica-se também que os católicos começam a perder sua força hegemônica, abrindo espaço para a expansão evangélica.

Pode-se supor que a "motivação inicial do engajamento político-partidário evangélico pós-88 tenha sido a moralização da política” (SMIDERLE, 2013, p. 141), mas também um retorno à valorização dos preceitos cristãos - se possível em todos os âmbitos da vida social. Essa questão está embutida na ação de militar em prol da cidade. Aquilo que eles querem que a cidade seja determina os eixos onde eles vão atuar.

Neste itinerário, apresentamos a seguir alguns cases de atuação evangélica que repercutiram no espectro midiático no período compreendido entre 2010 e 2018. Esses temas têm sido explorados por mim ao longo da pesquisa de doutorado por meio da etnografia digital, bem como através da minha inserção na rede política evangélica ${ }^{3}$, pois somente deste modo foi possível obter interação face a face e coletar depoimentos de importantes parlamentares e pastores da cena evangélica atual. Os conteúdos versam sobre projetos de lei, aproximações com o Poder Executivo estadual e federal, governança evangélica e "boicote" a questões culturais contrárias aos valores cristãos, construindo um quadro onde se veem distintas nuances das paisagens que os grupos evangélicos atualmente constroem. 


\section{Paisagens da experiência evangélica na mídia contemporânea}

A condição urbana que vivemos na sociedade brasileira, de contrariedades profundas, solicita a diferentes grupos a "busca de respostas relacionais para os grandes e pequenos problemas cotidianos" (MAFRA; ALMEIDA, 2009, p. 73). É nesse ínterim que os evangélicos operam para construir um outro sentido de urbanidade pautada nos valores e princípios cristãos.

Para Haroche (2008, p. 32), a finalidade da civilidade cristã seria conjugar norma moral enquanto preceito social e regra política; elucidar o significado de uma racionalidade nas condutas e mostrá-la não apenas como normas, preceitos ou ideais de uma época, mas também como comportamentos que refletem usos e costumes. Com base nesta reflexão, observamos que os evangélicos acreditam que, para que a sociedade atual tenha êxito é preciso, antes de tudo, redefinir suas formas de sociabilidade e reinscrever as existências que lhe dão vida num outro script, que lhes aponte um novo destino. Insinuando-se por meio de um discurso especializado, os evangélicos passam a elaborar certa espécie de "projeto de poder urbano", no sentido de terem um lugar de fala e de práticas que negociam e fazem valer sua presença na cidade. Este projeto de poder aponta para valores que contam com ampla adesão dos crentes. É um projeto político situando-se no campo semântico do discurso competente (CHAUÍ, 1989), que qualifica a dicção do saber especializado. Para tanto, estruturamse diferentes meios pelos quais os evangélicos organizam o mundo em polos antitéticos, estabelecendo as fronteiras entre o "bem" e o "mal" na metrópole. As pregações litúrgicas no ambiente do templo, os discursos de mídia em rádio e TV, bem como as narrativas no campo da internet são exemplos dessa questão.

Uma das figuras mais notáveis do discurso competente evangélico é o pastor Paschoal Piragine, presidente da Primeira Igreja Batista (PIB) em Curitiba. Bem antes do fervor das querelas religiosas eleitorais de 2018, Piragine começou a articular um movimento para que evangélicos ocupassem, efetivamente, as frentes dos principais núcleos governamentais de poder. Em 2010 foi divulgado um vídeo de sua pregação na PIB no qual ele argumenta contra o que chama de "institucionalização da iniquidade" O termo "iniquidade" para os evangélicos designa aquilo que é reprovável, contrário aos preceitos bíblicos. Exemplos considerados como iniquidade pelos evangélicos são: prostituição, homossexualidade, aborto, drogas, ideologia de gênero para crianças e adolescentes. Ter essas pautas aprovadas no Congresso nacional seria, para os 
evangélicos, uma forma de institucionalizar a iniquidade, o mal no país. Desta maneira, o conceito de "institucionalização da iniquidade" e a visão de que é preciso combatê-la foi capitaneado pelo pastor Piragine, numa clara referência às iniciativas do primeiro governo PT em 2010 para promover a legalização das uniões homoafetivas e a descriminalização do aborto.

O vídeo foi reproduzido em várias plataformas de mídia, como YouTube, Vimeo e Rede Super - transmissora de TV da PIB Curitiba -, de modo a conscientizar os cristãos de que a institucionalização da iniquidade é um dos discursos que fundamentam a "perda de Deus” na cidade. A partir da difusão do vídeo outros pastores ligados às Convenções Batistas se posicionaram firmemente, no rádio e na televisão, em favor do debate. A CNBB - Conferência Nacional dos Bispos do Brasil, em adesão ao movimento, publicou um documento intitulado "Apelo a todos os brasileiros e brasileiras" 5 , se posicionando com relação a esses assuntos.

Durante entrevista em maio de 2018, pastor Piragine relatou-me que a propagação do vídeo de pregação sobre a institucionalização da iniquidade foi uma das formas de expandir e consolidar o que se chama de cosmovisão cristã, que é a maneira de os evangélicos enxergarem o mundo e seus valores. A defesa do pastor é a de que os evangélicos tenham o exercício da liberdade para expressar o que consideram iniquidade de valores e, com isso, combatê-la. Enfatiza o cenário em que os evangélicos representam uma grande parcela da população - chegando próximo a 30\% dos brasileiros, segundo o IBGE -, mantendo a linha de pensamento que preserva os valores cristãos como base primordial da sociedade. Aos "opositores" dos evangélicos referindo-se à esquerda política e aos movimentos pró-gênero (LGBTQ+ e simpatizantes da perspectiva teórica e política dos estudos queer), Piragine questiona: o que eles vão fazer quando a população cristã evangélica chegar ao quantitativo dos $50 \%$ ?

Se você perguntar pra mim qual o modelo de família eu vou dizer pra você: não é qualquer ajuntamento humano porque qualquer ajuntamento humano não necessariamente é uma família na minha ótica. Agora, eu também tenho o direito de ter essa ótica; isso que é a minha grande crítica. Na minha perspectiva eu também tenho o direito - assim como o outro também tem - de dizer pra sociedade brasileira que a sua ótica não serve pra mim, que isso aqui vai virar uma bagunça. Assim como você tem o direito de dizer pra mim, quando vai pro palanque, que a minha ótica não funciona. $\mathrm{O}$ que eu não aceito é dizer "você não pode dizer isso porque você é religioso", e é isso 
que está se dizendo. Por que não posso? [Paschoal Piragine, Entrevista de campo, maio de 2018].

Para o pastor Piragine, existe um pensamento retroviral aos valores cristãos que está tomando vulto, e os evangélicos "precisam saber lidar com isso". A maneira mais eficaz de os evangélicos estarem na frente de batalha seria, portanto, elevar o grau de conhecimento e de comunicação por meio dos estudos acadêmicos e inserção no mundo pensante. Para ele, quanto mais os líderes evangélicos tiverem doutorado, pósdoutorado, serem profissionais de renome e prestígio público, mais os evangélicos ganharão força para mostrar que tem um projeto "melhor para esse mundo". Como exemplo, o pastor enaltece o fato de que no templo PIB Curitiba muitos membros são desembargadores, empresários, funcionários de liderança em empresas multinacionais. Alguns dos membros da PIB conseguiram, inclusive, criar núcleos da igreja em outros países, como Alemanha, Canadá e algumas nações africanas.

O pastor cita também a importância de se ter boas relações com o campo político-partidário. Eventualmente, Paschoal Piragine atua como conselheiro espiritual para os gestores públicos da cidade. Parlamentares do PSC - Partido Social Cristão de Curitiba, por exemplo, mantêm estreita coesão com a PIB Curitiba, concedendo à igreja diferentes diplomas e moções honrosas na Câmara Municipal e na Assembleia Legislativa do Paraná pela sua participação conjunta com o poder público em benefício da sociedade. Devido ao reconhecimento da igreja como identidade religiosa valorizada, a PIB Curitiba consegue obter auxílios da prefeitura e legitimar o acesso ao espaço público, tendo uma articulação fluida para realização de seus eventos e projetos sociais nos locais públicos da capital curitibana. Além disso, a PIB Curitiba é acionada pelo prefeito, por empresários e demais pessoas importantes no município quando há qualquer decisão a ser tomada que envolva a área central da cidade ou o bairro do Batel, onde a igreja está situada.

Ampliar a presença evangélica nos espaços de poder é também vista como importante para o pastor Luiz Roberto Silvado, presidente da Convenção Batista Brasileira e líder da Igreja Batista do Bacacheri - IBB, em Curitiba. Em sua opinião, ter evangélicos nos cargos administrativos ou em posições políticas favorece no momento em que os evangélicos são discriminados. Colabora, também, para ampliar a legitimidade da igreja no contexto da cidade. 
Relacionamentos favorecem. Isso é política no bom sentido, não é politicagem. Pra viver numa cidade você tem que fazer política de maneira correta, tem que saber se relacionar com as pessoas, conhecer as pessoas e ser conhecido. Aí você consegue influenciar e abençoar, consegue fazer parcerias, conversar, oferecer serviços. A gente está querendo levantar uma nova geração com participação significativa na política, mas que sejam de fato transformadores das estruturas de justiça. [L. Roberto Silvado, Entrevista de campo, junho de 2018].

A proximidade com as instâncias políticas permite ainda que a Igreja Batista do Bacacheri - IBB sirva de referência para realização de grandes eventos comunitários. Debates e audiências públicas, congressos municipais, entre outros eventos, frequentemente são realizados nos salões da IBB. Uma das principais cerimônias ocorridas na igreja foi o congresso para elaboração da política de prevenção contra as drogas de todo o estado do Paraná. O governo estadual promoveu o evento e a igreja cedeu o espaço. A ponte para intermediação foi realizada através de uma promotora de justiça, membro da Igreja do Bacacheri, que estava responsável por esse processo. "Ela nos consultou e nós dissemos sim, é uma forma de servir a cidade e ao estado. Por isso que nós estamos aqui”, louva o pastor Silvado.

Curitiba, "cidade-teste", tal como denominada por Paulo Leminski (1989), foi também laboratório para o boicote que se expandiu nacionalmente com relação à Exposição Queer Museu, no Santander Cultural de Porto Alegre-RS, em 2017. A Igreja Batista do Bacacheri - IBB assumiu a liderança do movimento em Curitiba de recomendar aos fiéis evangélicos que encerrassem contas-correntes que porventura mantinham no banco Santander. Em nota na web, a IBB publicou um comunicado onde decidiu encerrar sua conta no Banco Santander após a polêmica exposição artística que a igreja considerava zombar da fé cristã e fazer apologia à zoofilia e à pedofilia.

A postagem ${ }^{6}$, publicada no Instagram em 14 de setembro de 2017 , viralizou nas redes sociais e promoveu uma reação nacional nas igrejas evangélicas contra a exposição artística que o banco Santander promoveu em Porto Alegre. Os membros aprovaram a decisão e teceram notas na rede social elogiando a igreja. "Parabéns" e "Orgulho de vcs" foram os termos mais usados nos comentários. Dessa forma, para ocupar o espaço público e legitimar suas demandas, a fim de obter a eficácia, os evangélicos vêm renovando o formato das ações e manifestações tradicionalmente reconhecidas como políticas, por meio da constituição de redes virtuais de movimentos 
sociais e da comunicação mediada pela imagem (como teasers de Instagram e Twitter, entre outros).

O contexto cívico da região em que vivem dita o posicionamento dos evangélicos na política. Este é um bom insight para pensar a cidade: o espaço se confunde com a própria ordem social de modo que, sem entender a sociedade e suas redes de relações sociais e valores, não se pode interpretar como o espaço é concebido e suas gramáticas. De acordo com Roberto DaMatta (1997, p. 36), "nas sociedades onde o protestantismo se estabeleceu dominantemente, o movimento mais frequente é o de valorização dos conceitos religiosos no universo coletivo”. DaMatta também sugere uma ampliação do quadro de referência da moral protestante para mostrar que tais éticas não se situam somente na esfera econômica, mas são influenciadoras de outras áreas da conduta social.

No Rio de Janeiro - umas das capitais com maior quantitativo evangélico do país (71 evangélicos para cada 100 católicos, segundo o Pew Research Center, 2014) - a composição da paisagem evangélica na política tem sido importante para o fortalecimento de suas fronteiras. O fato de o governo municipal ser dirigido por pessoas que afirmam publicamente uma identidade evangélica - como o prefeito Marcelo Crivella e vereadores eleitos da "bancada evangélica" na Câmara, integrantes de partidos como $\mathrm{PRB}^{7}$ e $\mathrm{DEM}^{8}$ - favorece a estruturação política desse segmento religioso, que, muitas vezes, invoca a mediação divina para a solução de problemas públicos. Tais políticos que ocupam a legislatura municipal no Rio de Janeiro fazem do pertencimento evangélico um instrumento importante de atuação política.

Exemplo notável deste cenário foi a militância mercurial do vereador Alexandre Isquierdo, do Democratas (DEM), durante a tramitação do Projeto de Lei nº 1709/16, que trata do Plano Municipal de Educação do Rio de Janeiro. Isquierdo, que é membro da Assembleia de Deus Vitória em Cristo, do pastor Silas Malafaia, foi um dos maiores críticos do Plano e influente articulador para anular a inclusão da pauta que determinava sobre temas como sexualidade e gênero nas escolas de primeiro segmento do ensino fundamental (antigas $1^{\mathrm{a}}$ a $4^{\mathrm{a}}$ série). Em audiência pública realizada em 28 de junho de 2016 na Câmara de Vereadores do Rio, Isquierdo enfatiza que, "se depender da bancada dele, este plano "não vai passar"'. O Plano - cujo projeto original estava em tramitação desde 2013 - ainda não foi concluído, e as emendas que se seguiram pósaudiência pública de junho/2016 retiraram a temática da sexualidade das pautas de discussão. Ao consultar a tramitação atual do projeto, vê-se que não há quaisquer 
menções sobre as palavras "gênero" e "sexualidade" no documento ${ }^{10}$. Os debates sobre o Plano Municipal de Educação continuam na forma de audiências públicas e conferências. Em 2019, esses eventos foram previstos para ocorrerem em maio, segundo o calendário oficial ${ }^{11}$ da Secretaria Municipal de Educação do município.

Outro vereador evangélico, Inaldo Silva, do PRB, foi o autor da Lei No $6195^{12}$, de 09 de junho de 2017, que instituiu o Dia do Encontro Interdenominacional, popularmente conhecido, entre os evangélicos, como o "Dia da Igreja Sem Placa". A cada ano, sempre ao terceiro domingo de setembro, é comemorado na Câmara de Vereadores e em várias igrejas do Rio de Janeiro o Dia do Encontro Interdenominacional, pois, segundo Inaldo Silva:

só as placas denominacionais nos separam. O cara que é batista não é inimigo do assembleiano; o assembleiano não é inimigo de quem é metodista ou do católico. Porém a gente ainda vive numa facção. Então esse terceiro domingo de setembro que a gente comemora é o dia dessa igreja unida, aonde as placas não podem mais nos separar. $\mathrm{O}$ Cristo que nos une é maior do que as placas que nos separam. Ano passado a gente celebrou aqui (na Câmara) o primeiro encontro. Tinha igrejas de todos os segmentos, mostrando que a gente pode ter pensamentos diferentes, liturgias diferentes, e adorar e conviver juntos. [Vereador Inaldo Silva, Entrevista de campo, maio de 2018].

O vereador comenta que ter a igreja unida e capilarizá-la por meio da política seria uma estratégia forte para combater as desestruturas familiares. Para ele, a essência cristã deve pautar as diretrizes dos governantes, a fim de fazer a cidade "ser uma bênção". Uma vez que a ética cristã condicionaria o comportamento do governante, este não privilegiaria mecanismos escusos para roubar a saúde, a educação, a segurança pública. Na percepção de Inaldo, a cidade tende a ser mais abençoada quando tem uma governança cristã (não necessariamente evangélica), sendo assim a metonímia da bênção. Com o governante cristão, ele afirma, "dinheiro sobra, tudo sobra. Ele não tem duas mulheres, três mulheres pra gastar dinheiro... tudo sobra, né! O que traz discernimento é ter esses valores e ser bom no que faz" [Inaldo Silva, Entrevista de campo, maio de 2018].

Integrantes de partidos políticos pautados em valores cristãos acreditam que são nas grandes instituições como família, escola e igreja onde se aprende os princípios da ética e as diretrizes para os comportamentos públicos e privados, a fim de combater os "vícios" da cidade. Um assessor político do PRB, Y.S (iniciais fictícias), 38 anos, 
expressou a alcunha de que o Rio de Janeiro se transformou numa cidade "viciada”. Ele atribui tal cenário às dívidas superfaturadas para se concluir as Olimpíadas; às fraudes nas administrações hospitalares; ao excesso de investimento de verba pública em manifestações populares, como o Carnaval. O "antídoto" para essas mazelas seria uma administração onde o prefeito e o secretariado participam, juntos, de um mesmo pensamento para "ajudar a crescer a cidade”. Para o assessor político, "quando o justo governa o povo se alegra, mas quando o ímpio governa o povo geme” [Y.S., Entrevista de campo, maio de 2018].

Pergunto a ele se ao usar o termo “justo" está se referindo aos evangélicos. Ele afirma categoricamente que sim. Machado e Birman (2012, p. 55) traduzem a figura dos justos como mediadores político-religiosos que atuam enquanto "redentores" da constituição físico-moral da pessoa e da comunidade. Deste modo, o evangélico estaria enquadrado nesse referencial, já que ele "procura fazer mais a justiça em suas obras”. Seguindo este princípio, o assessor Y.S. defende que é interessante os evangélicos ocuparem diferentes cargos na prefeitura, conjugando a cosmovisão crista à capacidade administrativa.

Tendo uma cadeira aqui e eu precisando colocar alguém, se eu tenho um evangélico que não é capacitado e do outro lado uma pessoa não evangélica capacitada e íntegra, eu vou escolher esse último, porque ele vai, com a integridade e a capacidade dele, cuidar da cidade. Agora, se eu puder unir a integridade com a capacidade, e se junto disso vier uma pessoa evangélica, aí é top! [Assessor Y.S., Entrevista de campo, maio de 2018 ].

\section{Conclusão}

Examinei neste artigo algumas experiências amostrais para debater como os evangélicos produzem uma paisagem social utilizando-se dos canais de mídia. Televisão, redes sociais e plataformas de streaming, por exemplo, têm sido usadas para dialogar sobre questões morais e relacionais, as quais figuram, particularmente, como uma preocupação cotidiana e constitutiva da experiência urbana evangélica atualmente. Esses debates permeiam a paisagem evangélica em dois planos: o da materialidade e o da representação. Da materialidade porque o simbólico transforma-se em ações concretas, e da representação porque a subjetividade evangélica orienta as diretrizes e 
investimentos que eles executam para formatar seus projetos na metrópole, engendrando, factualmente, várias ilações de uma manipulação da paisagem.

Tudo, portanto, é disputado, e a presença dos acordos políticos é clara. Mais que isso: quando as narrativas cristas evangélicas são ampliadas na forma da lei se desenha um dado mais complexo, que é a questão do poder urbano e da disputa pela constituição de uma ordem na cidade. O senso comum e a esquerda política, especialmente, se perguntam, estarrecidos, como os evangélicos conseguem alçar tamanha representatividade nas arenas políticas. Vimos com esses exemplos que as coisas não ocorreram aleatoriamente, e que a constituição da ordem evangélica tem sido historicamente construída e organizada de modo bastante sofisticado e robusto. É uma ordem atualizada a todo instante.

Independentemente da corrente evangélica que se segue - se tradicional, histórica ou pentecostal, quando se trata de instrumentalizar o campo dos valores na cidade percebemos que os evangélicos se complementam e se apóiam. As maneiras de ver, de sentir, de pensar e exercer uma atitude cívica tornam-se objeto de interesse e investimento do capital evangélico nos dias atuais; passam a ser, elas mesmas, um vetor de valorização do cristianismo evangélico no contemporâneo.

A paisagem evangélica aparece cada vez mais como uma entidade relacional, que busca dar conta da totalidade das relações constitutivas nas metrópoles. Todos esses traços permitem caracterizar que a organização da paisagem pelos evangélicos traduz uma forma de organização da sociedade, além de uma ferramenta em que lideranças cristãs evangélicas procuram dar uma medida e um sentido às suas dinâmicas, ao seu projeto de sociedade.

Cada vez mais a problemática paisagística promovida pelos evangélicos contribui para mudar os questionamentos sobre a identidade dos territórios e o seu porvir. Neste sentido, o plano moral vetoriza o estado de sobrevida e de resistência da religião no urbano. "É preciso mudar a cidade" não é mais uma provocação old fashioned, mas um sentimento compartilhado pela maioria - tanto evangélicos quanto aqueles que abraçam suas causas.

\section{NOTAS}

* Socióloga, doutoranda e pesquisadora do Instituto de Pesquisa e Planejamento Urbano e Regional IPPUR/UFRJ. Bolsista CNPq. E-mail para contato: ritaantropologia@gmail.com

${ }^{1}$ Agostinho de Hipona (354-430 d. C.) polemizou com outras doutrinas ou manifestações religiosas de seu tempo: o Maniqueísmo, o Donatismo, o Pelagianismo e, também, enfrentou com muito rigor o Paganismo, existente entre a aristocracia do Império Romano de sua época. A produção da obra "Cidade de Deus" veio a continuar a campanha contra os pagãos que havia feito o bispo Agostinho durante o 
tempo de calamidades e ameaças, desde o fim do ano 410 até 412. Com a produção de sermões, conversas e carta aos governantes e cidadãos, Agostinho reproduziu seu ponto de vista sobre a cidade de Deus e a cidade terrena $\mathrm{O}$ conflito entre Agostinho e os pagãos contribuiu para que ele representasse o mundo dividido em duas classes de indivíduos e duas cidades. Agostinho observa que a cidade não era constituída unicamente de estruturas materiais, mas em primeiro lugar de indivíduos, de homens, de cidadãos. Nessa época, o homem não se imagina apenas como cidadão no Estado, mas também como um "cidadão do céu", membro de uma sociedade espiritual. No seio de sua obra encontra a solução para um problema fundamental, a saber: as relações do homem com Deus e o plano espiritual. Agostinho representa classicamente estes dois polos opostos como cidade: a cidade terrena e a cidade de Deus.

${ }^{2}$ Bispo canadense fundador da Igreja de Nova Vida, uma das precursoras do movimento pentecostal no Brasil. Acostumado a realizar cruzadas evangelísticas pelo mundo inteiro, Robert McAlister foi convidado por Lester Summeral, evangélico e ativista humanitário norte-americano, para participar de uma campanha evangelística no Maracanãzinho, Rio de Janeiro, em 1958. No ano seguinte, em 1959, McAlister veio morar no Brasil acompanhado da esposa e de seus filhos. Primeiro foi para São Paulo, mas na capital paulistana não logrou muitas oportunidades. Migrando para o Rio de Janeiro foi morar em Santa Teresa, onde começou a atuação da Igreja de Nova Vida, que tinha (e tem) como uma de suas características marcantes a evangelização para as camadas médias da sociedade carioca.

3 Importante destacar que minha aproximação com os influencers evangélicos foi possibilitada - e facilitada - pela criação de vínculos com uma comunidade crista evangélica da zona sul do Rio de Janeiro, cujos membros são próximos de pessoas que me conectaram a grandes lideranças evangélicas. Outro elemento que contribuiu para a inserção na rede foi minha posição enquanto pesquisadora. Sou socióloga de formação, no entanto, muitos dos evangélicos consideram-me como "jornalista”. Talvez por essa razão tenha havido, também, relativa abertura entre eles, pois observei que os evangélicos se sentem empoderados em seu lugar de fala e prestigiados por terem voz ativa em canais de mídia e pesquisas acadêmicas.

4. Disponível na plataforma de compartilhamento de vídeo VIMEO no endereço: https://vimeo.com/15585151. Acesso em: 05 mai. 2018.

${ }^{5}$ Disponível em: https://www.veritatis.com.br/apelo-a-todos-os-brasileiros-e-brasileiras/. Acesso em: 05 mai. 2019.

${ }^{6}$ Disponível em: https://www.instagram.com/p/BZCNUmUDx2L/. Acesso em: 06 mai. 2018.

7 Partido Republicano Brasileiro. Legenda $\mathrm{n}^{\mathrm{o}} 10$.

${ }^{8}$ Democratas. Legenda ${ }^{\circ} 25$.

9 Audiência Pública sobre o Plano Municipal de Educação. Disponível em: Disponível em: https://www.youtube.com/watch?v=ep_819nHPKo

${ }^{10}$ A íntegra do projeto de lei 1709/2016 pode ser consultada na página da Câmara de Vereadores do RJ. Ao seguir as seções Atividades Parlamentares > Proposições > Busca Específica, é possível encontrar o nome dos parlamentares autores das emendas ao projeto, e verificar quais emendas estão em tramitação. Pelo mesmo caminho será possível verificar se o projeto foi votado na íntegra, para então ascender ao estatuto de Lei. Disponível em:

http://www.camara.rj.gov.br/controle_atividade_parlamentar.php?m1 =materias_leg\&m2=9a_Leg\&m3 =prolei\&url=http://mail.camara.rj.gov.br/APL/Legislativos/scpro1316.nsf/Internet/LeiInt?OpenFor m. Acesso em: 02 mai. 2018.

11 Disponível em: http://prefeitura.rio/web/sme/plano-municipal-de-educacao. Acesso em: 05 mai. 2018.

12 Disponível em:

http://mail.camara.rj.gov.br/APL/Legislativos/scpro1720.nsf/249cb321f17965260325775900523a42/ e613a15b1e79foe7832580c9004fdco7?OpenDocument\&Start=1. Acesso em: 05 maio de 2018. 


\section{REFERÊNCIAS BIBLIOGRÁFICAS}

AGOSTINHO, Santo. A Cidade de Deus. Volumes I e II. Lisboa: Fundação Calouste Gulbenkian, 1996.

ARISTÓTELES. Política. (Edição completa). São Paulo: Matin Claret, 2006.

AZEVEDO, Artur. A capital federal. São Paulo: Martin Claret, 2002.

BESSE, Jean-Marc. O gosto do mundo: exercícios de paisagem. Rio de Janeiro: EdUERJ, 2016.

BOURDIEU, Pierre. Os usos sociais da ciência: Por uma sociologia clínica do campo científico. São Paulo: Unesp, 1997.

BURITY, Joanildo. Religião e cidadania: alguns problemas de mudança sociocultural e de intervenção política. In: BURITY, Joanildo (Org.) Religião e Cidadania. São Cristóvão (Sergipe): Editora UFS, 2010.

CHAUÍ, Marilena. Cultura e democracia: o discurso competente e outras falas. São Paulo: Cortez, 1989.

COELHO, Fabiano de Souza. Agostinho e a dialética das duas sociedades: a cidade de Deus e a cidade terrena. In: Revista Ágora, Vitória, n.15, 2012, p. 120-131.

DAMATTA, Roberto. A casa e a rua: espaço, cidadania, mulher e morte no Brasil. Rio de Janeiro: Rocco, 1997.

GILSON, Ettiene. Evolução da Cidade de Deus. São Paulo: Herder, 1965.

HAROCHE, Claudine. A condição sensível. Rio de Janeiro: Contracapa, 2008.

HEIDEGGER, Martin. Ser e Tempo. Petrópolis: Vozes, 1995.

IBGE. Censo Demográfico 2010. Resultados Gerais da Amostra. Disponível em: https://sidra.ibge.gov.br/pesquisa/censo-demografico/demografico-2010/amostra-caracteristicasgerais-da-populacao-religiao-e-deficiencia. Acesso em: 01 mai. 2019.

LIPOVETSKY, Gilles; CHARLES, Sébastien. Os Tempos Hipermodernos. São Paulo: Barcarolla, 2004.

LEMINSKI, Paulo. Nossa linguagem. In: Edições Leite Quente. Curitiba, Fundação Cultural de Curitiba, v.1, n.1, mar. 1989 .

MACEDO, Joaquim Manuel. A luneta mágica. São Paulo: Martin Claret, 2015.

MACHADO, Carly; BIRMAN, Patrícia. A violência dos justos: evangélicos, mídia e periferias da metrópole. In: Revista Brasileira de Ciências Sociais, vol. 27, n. 80, p. 55-69.

MAFRA, Clara; ALMEIDA, Ronaldo (Orgs.). Religiões e Cidades: Rio de Janeiro e São Paulo. São Paulo: Terceiro Nome, 2009.

OLIVEN, Ruben George. Antropologia de grupos urbanos. Petrópolis: Vozes, 2011.

PECHMAN, Robert Moses. Cidades estreitamente vigiadas: o detetive e o urbanista. Rio de Janeiro: Casa da Palavra, 2002.

PEW RESERACH CENTER. Religion in Latin America: widespread change in a historically catholic region. Disponível em http://www.pewforum.org/ 2014/11/13/religion-in-latin-america/. Acesso em: 01 mai. 2019.

SEVCENKO, Nicolau. Orfeu extático na metrópole: São Paulo, sociedade e cultura nos frementes anos 20. São Paulo, SP: Companhia das Letras, 1992. 
SILVA, Drance Elias. Religião, dádiva e cidadania. In: BURITY, Joanildo (Org.) Religião e Cidadania. São Cristóvão (Sergipe): Editora UFS, 2010.

SMIDERLE, Gustavo. Modernização à Brasileira. O tempero pentecostal na política nacional. Rio de Janeiro: Outras Letras, 2013.

\title{
SOCIAL LANDSCAPES AND AN EVANGELIC EXPERIENCE IN THE MEDIA: COSMOVISIONS OF A COMPETENT SPEECH
}

\begin{abstract}
THIS PAPER AIMS TO EXPLORE HOW EVANGELICALS PRODUCE A SOCIAL LANDSCAPE USING MEDIA CHANNELS. TELEVISION, SOCIAL NETWORKS, AND STREAMING PLATFORMS, FOR EXAMPLE, HAVE BEEN USED TO TALK ABOUT MORAL AND RELATIONAL ISSUES, WHICH APPEAR PARTICULARLY AS A DAILY CONCERN AND CONSTITUTIVE OF EVANGELICAL URBAN EXPERIENCE TODAY. THE CONCEPT OF LANDSCAPE HERE IS ANALYZED FROM AN ANTHROPOLOGICAL PERSPECTIVE, IN ORDER TO DEMONSTRATE THAT THE DIFFERENT PANORAMAS CONSTRUCTED BY EVANGELICALS ARE AN INSEPARABLE HISTORICAL PHENOMENON OF THE EMERGENCE OF HYPERMODERNITY, BASED ON THE IDEALS OF WORLD TRANSFORMATION AND THE FORMULATION OF PRACTICES FOR THE SURVIVAL OF RELIGION IN THE NEXT GENERATIONS. BASED ON THE REFLECTIONS DEVELOPED BY THEORISTS SUCH AS ROBERT PECHMAN (2002) AND JEAN-MARC BESSE (2016), I DESCRIBE THE STRATEGIES THAT EVANGELICAL GROUPS LINKED TO THE GOVERNMENT POWER CORES AND MEDIA INFLUENCE ELABORATE TO ELABORATE A CERTAIN KIND OF "URBAN POWER" PROJECT, IN THE SENSE OF HAVING A PLACE OF SPEECH AND PRACTICES THAT NEGOTIATE AND ENFORCE THEIR PRESENCE IN THE CITY.
\end{abstract}

KEYWORDS: EVANGELICALS; URBANITY; URBAN POWER; LANDSCAPE.

\section{PAYSAGES SOCIAUX ET L'EXPÉRIENCE ÉVANGÉLIQUE DES MÉDIAS: COSMOVISIONS D'UN PAROLE COMPÉTENT}

RÉSUMÉ: CET ARTICLE A POUR OBJECTIF D'EXPLORER COMMENT LES ÉVANGÉLIQUES PRODUISENT UN PAYSAGE SOCIAL EN UTILISANT LES CANAUX MÉDIATIQUES. LA TÉLÉVISION, LES RÉSEAUX SOCIAUX ET LES PLATEFORMES DE DIFFUSION EN CONTINU, PAR EXEMPLE, ONT ÉTÉ UTILISÉS POUR PARLER DE PROBLĖMES MORAUX ET RELATIONNELS, QUI APPARAISSENT PARTICULIĖREMENT COMME UNE PRÉOCCUPATION QUOTIDIENNE ET CONSTITUTIVE DE L'EXPÉRIENCE ÉVANGÉLIQUE URBAINE D'AUJOURD'HUI. LE CONCEPT DE PAYSAGE EST ICI ANALYSÉ D'UN POINT DE VUE ANTHROPOLOGIQUE, AFIN DE DÉMONTRER QUE LES DIFFÉRENTS PANORAMAS CONSTRUITS PAR LES ÉVANGÉLIQUES SONT UN PHÉNOMĖNE HISTORIQUE INDISSOCIABLE DE L'ÉMERGENCE DE L'HYPERMODERNITÉ, FONDÉ SUR LES IDÉAUX DE LA TRANSFORMATION DU MONDE ET LA FORMULATION DE PRATIQUES POUR LA SURVIE DU MONDE. RELIGION DANS LES PROCHAINES GÉNÉRATIONS. À PARTIR DES RÉFLEXIONS DÉVELOPPÉES PAR DES THÉORICIENS TELS QUE ROBERT PECHMAN (2002) ET JEAN-MARC BESSE (2016), JE DÉCRIS LES STRATÉGIES DÉVELOPPÉES PAR LES GROUPES ÉVANGÉLIQUES LIÉS AUX NOYAUX DU POUVOIR GOUVERNEMENTAL ET À L'INFLUENCE DES MÉDIAS POUR ÉLABORER UN CERTAIN TYPE DE PROJET DE «POUVOIR URBAIN». , DANS LE SENS DE DISPOSER D'UN LIEU DE DISCOURS ET DE PRATIQUES QUI NÉGOCIENT ET RENFORCENT LEUR PRÉSENCE DANS LA VILLE.

MOTS-CLÉS: ÉVANGÉLIQUES; L'URBANITÉ; POUVOIR URBAIN; PAYSAGE 